\title{
Different ways of synergistic effects of human resource management (HRM) practices on organizational performance: A method of $2+2=5$
}

\author{
Qura-tul-aain Khair* and Muhammad Mohtsham Saeed \\ International Islamic University, Islamabad, Pakistan.
}

Accepted 17 May, 2011

\begin{abstract}
Synergy is a main characteristic of human resource management (HRM) system. It highlights the hidden characteristics of HRM system. This research paper has empirically tested that internally consistent and complementary HR practices/components in the HR system are more able to predict and enhance the organizational performance than the sum of individual practice. The data was collected from the sample of 109 firm respondents of service industry through convenience sampling technique. The major finding of this research highlighted that configurational approach to synergy or the HRM system as a whole has an ability to enhance the organizational performance more than by the sum of individual HRM practices of HRM system. Hence, confirming that the whole is greater than the sum of individual parts.
\end{abstract}

Key words: Human resource management practices, synergy, and organizational performance.

\section{INTRODUCTION}

Strategic human resource management is concerned with the understanding of human resource contribution to the firm's objectives, goals, and better firm's performance through sustained competitive advantage (Barney and Wright, 1998). Strategic human resource management has shifted the theoretical focus from an individual human resource practice to an integrated framework of different human resource practices in the form of a system or HR bundle (Mayson and Barrett, 2006).

SHRM is a combination of supportive and complementary human resource practices to develop employees' skills, knowledge and abilities (SKA) with the intention to support business strategy. Business requisite employee SKAs are anticipated to be rare, valuable, inimitable and non-substitutable for gaining competitive advantage (Colvin and Boswell, 2007; Barney, 1991). An organization with substantial number of employees has labor cost, which is normally high percentage of total costs. Arguably, it is human resource where more focus is needed to improve the organizational performance and lowering the overall organizational cost (Alam, 2009).

Human SKAs and behaviours are responsible to give

\footnotetext{
"Corresponding author. E-mail: dawnmbait@hotmail.com.
}

an organization a direction towards the competent success. These human SKAs and behaviours are controlled by properly aligned human resource practices of HR system (Wei, 2006).

Barney's (1991) resource-based view (RBV) has strong implication for strategic human resource management (Barney and Wright, 1998; Wright and McMahan, 1992) by highlighting the importance of human resource as internal organizational resource eligible to sustain competitive advantage. The HR system, having internally consistent HR practices, becomes coherent, complementary and creates synergy in a sense that each HR practice supports the effectiveness of other practice (Chadwick, 2010; Wei, 2006).Therefore, the effectiveness of HR system as a whole is greater than the individual parts/ practice (Delery, 1998). This complementary and synergetic nature of horizontally fit HR system has ability to create the competitive advantage for an organization (Alam, 2009).

For managers and practitioners, the important things to keep in notice are components of HRM system and the nature of synergy. Different types of components of HRM system would produce synergies of different strengths. The rational manager will select those HR practices in a HRM bundle which will produce most synergistic effects on organizational performance in better way. 
Based on RBV, the aim of this research paper was to highlight the synergistic aspects of human resource management when acting as a system and when as a sum of individual HR practices. In this study, we have articulated the effectiveness of HR system as a whole and as a sum of individual practices on the organizational performance in the service industry of Pakistan. Secondly, it has been empirically tested that internally consistent and complementary HR practices in the HR system are more able to predict and enhance the organizational performance than the sum of individual practice.

\section{LITERATURE REVIEW}

Synergy can be defined in several ways because this concept has extended across many fields under variety of labels. Milgrom and Roberts (1992) defined:

"The synergy or complementarity as a circumstance when doing more of an organizational activity increases the returns to doing more of other related activities (c.f. Chadwick)."

In other fields, this concept is known as complementarity, bundling, horizontal fit, congruence, internal fit, alignment, configuration, interdependence, supermodularity, and coupling (Chadwick, 2010). Although some minute differences do present among these concepts but they are similar under the general idea of $2+2=5$, 'the whole is greater than the sum of individual parts/practices' (Chadwick, 2010; Delery and Doty, 1996).

Going through SHRM literature, two types of synergy (or fit) are found affecting the organizational performance. The first type of synergy is between the HR systems and the external factors like business strategy and technology. This type of synergy is known as external fit, vertical fit or external alignment in the SHRM literature. Second type of synergy is interdependence among the HRM practices or its components. This interdependence is famously known as horizontal fit, bundling, internal fit, internal alignment, configuration and complementarities.

Elaborating these two types of synergy or fit, Wei (2006) described horizontal fit as an alignment and consistency among the HR practices, such as selection training, compensation, employee relationship, and performance appraisal etc., in such a way that each HR practice supports each other (Baird and Meshoulam, 1988). Whereas, vertical fit involves those HR strategies that are integrated with the business strategy and support organizational objectives. The HR practices of vertical fit are also internally consistent, mutually dependent and coherent with firm's business strategy (Wei, 2006). As both types of HR fits enhance the competitiveness of a in a systematic way or in the form of bundle.

Huselid et al. (1997) divided HRM activities into two parts, technical HRM activities and strategic HRM activities. Considering the Barney's (1991) resourcebased view, Huselid et al. (1997) division of HR activities into two categories goes along both types of HR fits (Wei, 2006). Strategic HRM activity goes with the concept of vertical fit. Whereas, technical HRM bridges a series of HR practices that not only support each other but also enhance the effectiveness of one another (Alam et al., 2010). These activities include attracting skillful employees, inserting them in suitable positions; train them to work in specific way, and motivating them to add more useful schemes to organizational objectives (Wei, 2006). So, systematic design is required to coordinate these separate HRM practices to achieve the horizontal fit. This idea of horizontal fit has changed the SHRM researcher's focus from individual HRM practices to the entire HRM system.

\section{Synergistic effects of HRM practices}

Over the past decade, the researchers of HRM and the organizational performance literature have showed undeviating consensus that the synergy exists among the HRM practices (Michie and Sheehan, 2005; Guerrero and Barraud-Didier, 2004; Delery and Doty, 1996; Milgrom and Roberts, 1992). The whole HRM system has quality impact in enhancing the overall organizational performance as compare to the sum of its practices individually.

One of the reasons for this could be that when HRM system affects the organizational performance, this effect cannot be transformed into the effects of individual HRM practices. So, on the whole all practices in the HRM system support and enhance each other to increase the overall organizational performance (Chadwick, 2010).

When it is said that whole is greater than the sum of individual parts then two approaches of synergy can be extracted from this statement. In other words, the HR system can affect the overall organizational performance:

(1) By the individual components/practices effect to synergy, (2) by the configurational or interactive effects of HRM practices in the HRM system.

The individual HRM practice synergy approach is based in the assumption that each HRM practice in the HRM system has its independent effect on the organizational performance. If HRM practices interact with each other then this interaction is not much significant or relevant for their effectiveness as a system (Chadwick, 2010). Independent effects to synergy are aimed at that $2+2$ is not less than four. In this approach each HR function has its own independent impact on the organizational firm so it is important to arrange a variety of HR practices. In other words, functionally, the HR practices in the HR system are not equivalent with respect to organizational performance. In contrast, the whole HR system or configurational approach to synergy is built on the 


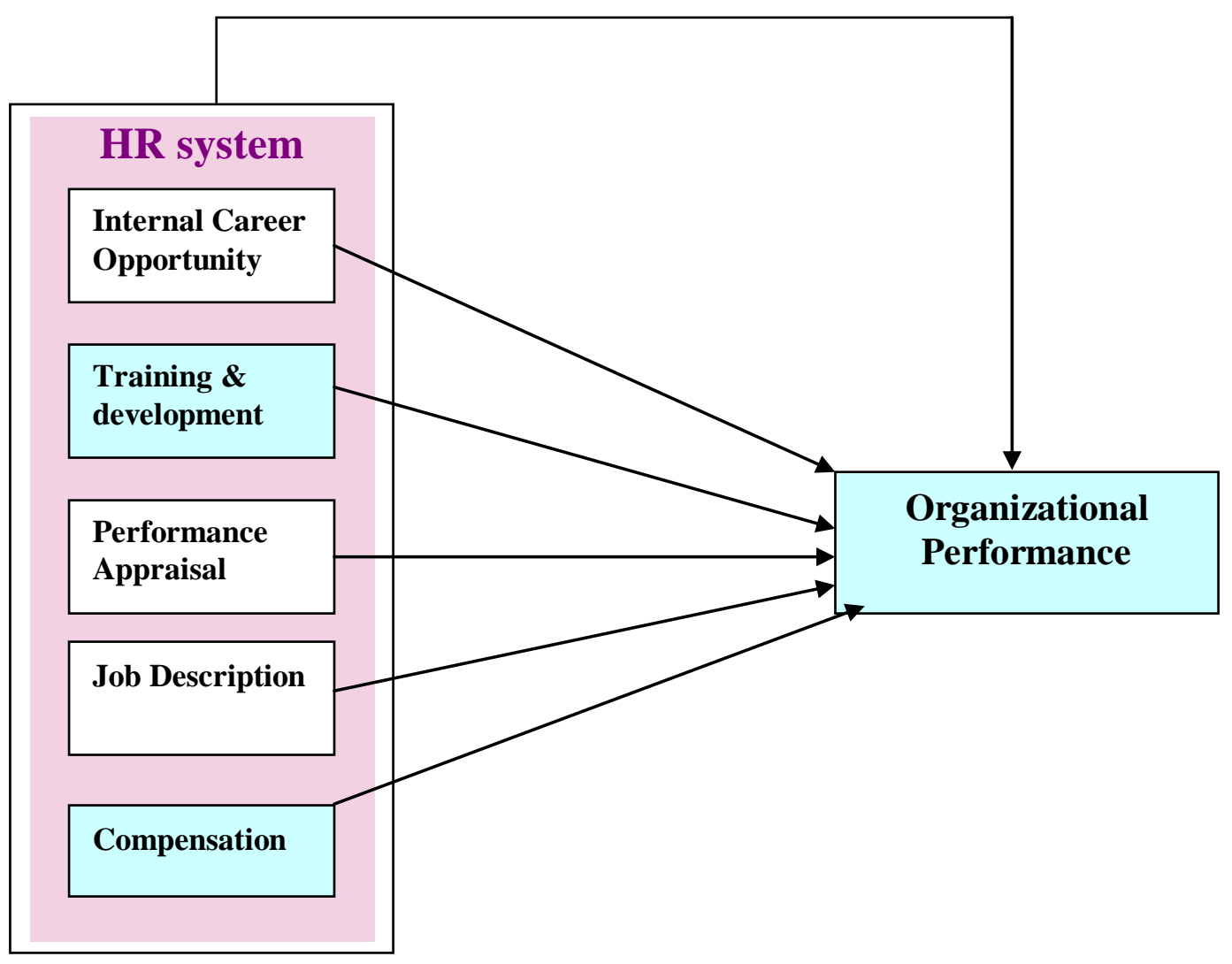

Figure 1. Theoretical framework.

assumption that HRM practices are mutually dependent upon each other and reinforce each other at their maximum level to ensure the utmost HRM system effectiveness. This approach considers the HRM practices as functionally equivalent in HR system with respect to the organizational performance. This functionally equivalence makes the HR practices in the configurational approach mutually reinforcing and complementary (Delery and Doty, 1996). According to Delery and Doty (1996) the functionally equivalent configurational approach is comprised of multiple equally effective combinations of HRM practices. The effect of whole HR system to synergy is aimed at $2+2=5$. In configurational approach HR practices not only interact with each other to create synergy but also exploit the reciprocal interdependence among system HRM practices (Chadwick, 2010).

Many researchers have found that although both approaches to synergy have positive and enhancing impact on the organizational performance but the configurational or whole HRM system is more able to enhance the organizational performance than each of the individual practices. According to Guerrero and BarraudDidier (2004) research study, the individual HRM practices yielded various intensities of variation in the profitability, such as empowerment explained 13.3\%, communication $9.7 \%$ and training $4.7 \%$ of variation in the profitability but the effect of whole HRM system was highest of all individual HR practices. It was $14.1 \%$, showing more synergistic effect on performance outcome.

Similarly, Michie and Sheehan (2005) have also found that additive or whole HRM system had more contribution in enhancing the sales growth, labor productivity and profitability than by the sum of individual HRM practices. Figure 1 is representing theoretical framework. So the hypotheses for testing are:

$\mathrm{H}_{1}$ : HRM system has positive relationship with the organizational performance.

$\mathrm{H}_{2}$ : An individual HRM practice has positive relationship with the organizational performance.

$\mathrm{H}_{3}$ : HRM system is more able to enhance the organizational performance than a sum of individual HRM practices.

\section{METHODOLOGY}

\section{Sample and procedure}

Data for this study was collected from service industry where the employees were in frequent contact with customers and required a 
Table 1. Summary of measuring instrument.

\begin{tabular}{llcc}
\hline Research concept & Original instrument author & No. of item & Cronbach's alpha \\
\hline Organizational performance & Green (2002) & 7 & 0.96 \\
HRM system & Delery and Doty (1996) & 15 & 0.72 \\
I_Cr_Opp & Delery and Doty (1996) & 4 & 0.64 \\
Training & Delery and Doty (1996) & 4 & 0.83 \\
Perf_App & Delery and Doty (1996) & 2 & 0.80 \\
Job_Des & Delery and Doty (1996) & 4 & 0.78 \\
Comp. & Delery and Doty (1996) & 1 & -- \\
\hline
\end{tabular}

great deal of behaviour manipulation for proper dealing and achieving the firm's goal in strategic manners. Target population was comprised of banks, restaurants, courier services, travel agencies, insurance companies, telecom industry, etc. Basically, this study was designed to explore the causal relationships among the variables. As it was not possible to reach all service providing firms due to geographical dispersion so it was decided to use convenience-sampling method to obtain the study sample. Initially, 160 questionnaires were distributed with the assurance that respondents could understand all questions. Out of 160 questionnaires, 117 questionnaires were returned, of which 8 questionnaires were with incomplete responses so these were discarded. 109 questionnaires were eligible for this study. So, acceptable response rate was $68 \%$. Each questionnaire was delivered to respective respondent and record was kept on separates sheet that contained respondents' name, organizations' names, and respondents' contact numbers. Three to four days were given to each respondent to fill up the questionnaire. Before going to collect questionnaires, phone calls were made to remind and confirm that questionnaires had been filled.

\section{Measurements}

\section{Human resource strategy}

For measuring HR strategy of firms, HR practices of Delery and Doty (1996) were selected. This study selected five categories of HR practices, which included $15 \mathrm{HR}$ practice statements. The overall Cronbach Alpha of these HRM system statements was 0.72. Each HRM practice included internal career opportunity, training and development, performance appraisal, job description and compensation. Cronbach alpha of each HR practice in available in Table 2.

Respondents answered these statements on 7-point Likert-type scales ranging from 7 to $1.7=$ total agreement, $6=$ generally agree, $5=$ slightly agree, $4=$ neither agree nor disagree, $3=$ slightly disagree, $2=$ generally disagree and $1=$ total disagreement. All HRM questions were already designed in such a way that the higher score was considered more tended to be HR practices of accumulator HRM system and lower score was closer to the HR practices of utilization HRM system (Wang and Shyu, 2008). According to Delery and Doty (1996) the HRM system statements were internally consistent and supportive for each other as the maximum value of these statements was indicating specific type of HRM system. The decision of higher score for accumulator HRM system, lower score for utilizer HRM system and middle average score for facilitator HRM system was based on the approach suggested by Govindarajan (1988) and operationally followed by Delery and Doty (1996). Delery and Doty (1996) specified facilitator as the mean value for each of the relevant variables whereas accumulator and utilizer were specified as plus or minus one standard deviation from the mean of each variable respectively. As
Delery and Doty (1996) have taken all HRM statements on 7-point Likert scale, their mean value for accumulator HR bundle ranges from 5.1 to 7 , for facilitator HR bundle from 2.6 to 5 and for utilizer HR bundle from 1 to 2.5. This study had also adopted the same scheme for identifying the synergetic effect of each HR practices system on the organizational performance.

\section{Organizational performance}

Organizational performance being a dependent variable was measured through self-reported or self-typed employee performance (Bird and Beechler, 1995; Conant et al., 1990). Performance was measured on the basis of perceived average $\mathrm{ROI}$, average profit, profit growth, average ROS, average market share growth, average sales volume growth, and average sales growth over past three years (Green, 2002). The Cronbach's alpha of organizational performance was 0.96 . In the questionnaire, each question was measured on 7 -items scale ranging from 7 to $1,7=$ well above industry average, $6=$ generally above industry average, $5=$ slightly above industry average, $4=$ neither above nor below and $3=$ slightly below industry average, 2= generally below industry average and $1=$ well below industry average. Executives or alternatively managerial assessments were considered for measuring financial performances due to their consistent understanding with firm's internal and external performance objectives (Conant et al., 1990). Table 1 is represents the summary of measuring constructs.

\section{Control variables}

Some variables were controlled, as they were not allowed to differ freely with independent variables. Based on previous studies, some control variables were included to get actual impact of HR practices bundle on the organizational performance as much as possible. Control variables were organizational size and organizational age in respective firm. Organizational size and organizational age may be more likely to have influence over well-developed HR practices (Bennett et al., 1998). Organizational size was controlled by taking natural logarithm of total number of employees (Wang and Shyu, 2008; Delery and Doty, 1996) whereas organizational age was measured through ordinally interval scale, which was divided into four sets of year categories as less than 10 years, 11 to 20 years, 21 to 30 years and more than 30 years.

For data analysis SPSS 16 was used. Data was analyzed through correlation and regression techniques.

\section{RESULTS AND ANALYSES}

Table 2 represents the mean, standard deviation and correlation matrix. Overall table is showing quite 
Table 2. Mean, standard deviation and correlation matrix.

\begin{tabular}{|c|c|c|c|c|c|c|c|c|c|c|}
\hline Research concept & Mean & Std. Dev & 1 & 2 & 3 & 4 & 5 & 6 & 7 & 8 \\
\hline HRM system & 5.45 & 0.713 & $(0.72)$ & & & & & & & \\
\hline Org_Perf & 5.45 & 0.86 & $0.524^{* *}$ & $(0.96)$ & & & & & & \\
\hline I_Cr_Opp & 5.15 & 1.09 & $0.788^{\star *}$ & $0.354^{\star *}$ & $(0.64)$ & & & & & \\
\hline Training & 5.65 & 1.11 & $0.684^{* *}$ & $0.271^{\star *}$ & $0.635^{* *}$ & $(0.83)$ & & & & \\
\hline Perf_App & 5.61 & 1.21 & $0.697^{* *}$ & $0.224^{*}$ & $0.639^{* *}$ & $0.471^{* *}$ & $(0.80)$ & & & \\
\hline Job_Des & 5.58 & 0.64 & 0.163 & $0.198^{*}$ & 0.042 & $-0.341^{* *}$ & 0.068 & $(0.78)$ & & \\
\hline Comp. & 5.27 & 1.93 & $0.628^{* *}$ & $0.317^{\star *}$ & $0.361^{* *}$ & $0.402^{\star *}$ & $0.422^{* *}$ & $0.208^{*}$ & -- & \\
\hline Tot_Emp_No & 3.79 & 1.89 & 0.040 & 0.075 & 0.106 & 0.032 & 0.014 & 0.043 & 0.008 & -- \\
\hline Org. age in years & 2.33 & 1.12 & 0.053 & 0.005 & 0.047 & 0.001 & 0.110 & 0.006 & 0.109 & $0.217^{*}$ \\
\hline
\end{tabular}

Org_Perf is organizational performance, Tot_Emp_No is total employee number, I_Cr_Dev is internal career opportunity, Perf_App is performance appraisal, Job_Des is job description, and Comp. is compensation. Std. Dev is standard deviation. Diagonal figures in brackets are showing Cronbach's Alphas. ${ }^{* *}$ Correlation is significant at the 0.01 level (2-tailed). ${ }^{*}$ Correlation is significant at the 0.05 level (2-tailed).

significant results. The association between HRM system and organizational performance $(r=0.524, p<0.01)$ is strong and positive. This confirms the $\mathrm{H}_{1}$. The strength of relationship between organizational performance and each individual HRM practice were; internal career opportunity $(r=0.354, p<0.01)$, training $(r=0.271, p<$ $0.01)$, performance appraisal $(r=0.224, p<0.05)$, job description $(r=0.198, p<0.05)$ and compensation $(r=$ $0.317, p<0.01$ ). This also supports $H_{2}$. The strength of association between HRM system as a whole and organizational performance is stronger than the individual HRM practices' association with the organizational performance. $\mathrm{H}_{3}$ is also supported to some extent.

Other significant correlations among several HRM practices indicated that these practices are not completely independent. The strength of association among the individual HRM practices was quite significant among some HRM practices. The correlation between internal career opportunity and training $(r=0.635, p<$ 0.01 ) was in accordance with the Delery and Doty's (1996) internal employment system. Simultaneously, significant relationship was present between training and performance appraisal $(r=0.471, p<0.01)$. This indicated that training was playing its role in helping the employees to get fit with internal career opportunity. In defender business strategy, there is usually shifting from one level of organization to other, sometimes for promotions and sometimes in the form of job rotation. So training usually plays meaningful role for developing the necessary abilities and skills in employees according to the job requirements. This was clearly indicated by the increasing trend of relationship between training and performance appraisal. The positive relationship between internal career opportunity and performance appraisal $(r$ $=0.639, p<0.01$ ) showed that employees hired from within the organization were normally evaluated through quantifiable results. This finding was further strengthen by the relationship of compensation with performance appraisal $(r=0.422, p<0.01)$ and training $(r=0.402, p<$ $0.01)$. Individual HRM practices, including internal career opportunity $(r=0.788, p<0.01)$, training $(r=0.684, p<$ $0.01)$, performance appraisal $(r=0.697, p<0.01)$, and compensation $(r=0.628, p<0.01)$, with the HR system is strong and positive. One reason for these strong associations could be that each individual HRM practice is a part of HR system. So each HRM practice is in fact controlling the some trend of overall HR system.

The correlation between organizational and total number of employees $(r=0.217, p<0.05)$ in that organization showed that those organizations with more number of years in a business had more experienced people and more number of employees. This is may be due to well-established HRM system over a time.

Figure 2 represents the general trend of the association between the HRM system and organizational performance. As the value of HRM system is increasing the organizational performance is also increasing accordingly. This indicates that those organizations with well-established HRM system are more able to increase their organizational performance. This also indicate that as most of the HRM system values lay between 5 and 7 so it shows accumulator HRM system trends. Majority of the organizations adopt this HRM system (Huang, 2001) due to it ability to enhance the organizational performance.

Table 3 represents the regression results. Regression analysis is statistical technique, which analyse the linear relationship between a dependent variable and independent variables. Table 3 also represents six models. Model 1 has considered the HRM system as a whole or configurational approach to enhance the organizational approach. Whereas, Models 2, 3, 4, 5 and 6 is showing the results of individual HRM practices and their impact on the organizational performance. Models 2, $3,4,5$ and 6 are showing regression results of internal career development, training, performance appraisal, job 


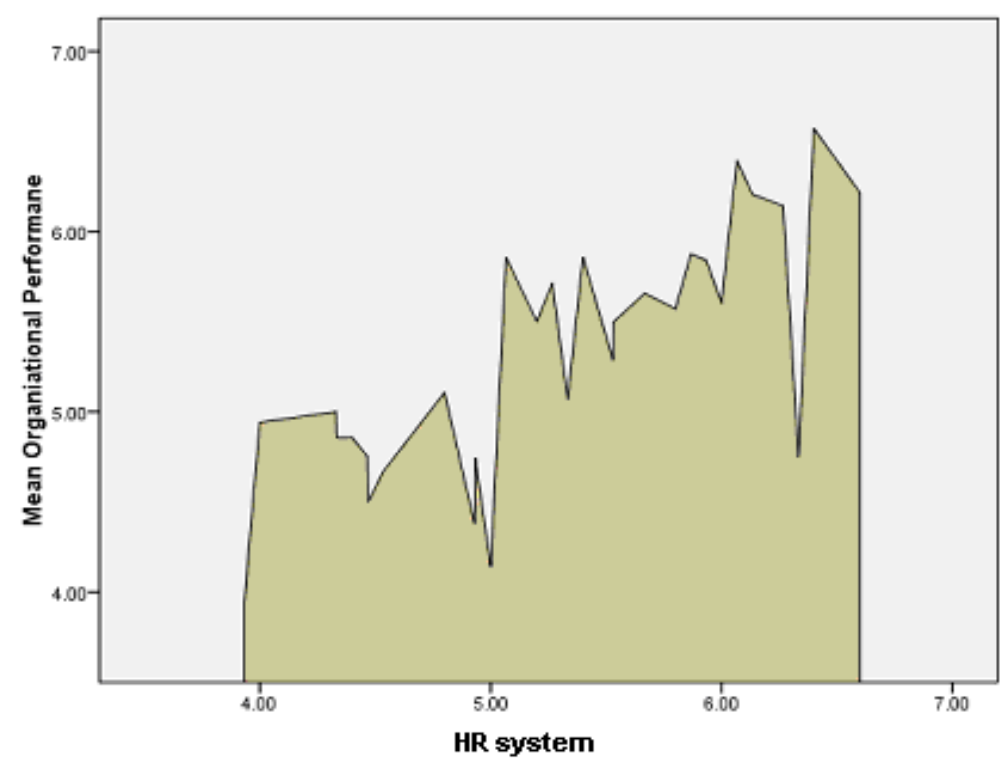

Figure 2. General trend of association between HRM system and organizational performance.

description and compensation respectively.

In Model 1, the $\mathrm{R}^{2}(0.275, \mathrm{p}<0.01)$ indicated that HRM system as a whole along with control variables was able to explain $27.5 \%$ of variation in the organizational performance. Whereas individual HRM practices like internal carer opportunity showed $R^{2}(0.045, p<0.10)$, training had $R^{2}(0.076, p<0.10)$, performance appraisal had $R^{2}(0.051, p<0.10)$, job description had $R^{2}(0.042, p$ $<0.10)$, and compensation had $R^{2}(0.036, p<0.10)$. Each individual HRM practice showed quite low values for $R^{2}$, this indicated that individually each HRM practice was able to explain very less amount of variation in the organizational performance. The added sum of $R^{2}$ of all individual HRM practice was 0.25 , this indicated that the ability of sum of individual HRM practice to explain the variation in organizational performance was less than the HR system as whole $R^{2}(0.275, p<0.01)$.

This supported the $\mathrm{H}_{3}$. This finding was in accordance with the (Guerrero and Barraud-Didier, 2004). Similarly, in models 2, 4, 5 and 6, the F statistics of individual HRM practice were insignificant except training in model $3(\mathrm{~F}=$ 2.86, $\mathrm{p}<0.05)$. Whereas Model 1 showed overall significant result $(F=13.27, p<0.01) . F=13.27$ was a compared value of the amount of variation in the organizational performance explained by HRM system to the unexplained variation or error variance. The value of $F$ was large enough to indicate that organizational performance had more explained value than error variance (Hair et al., 2003). $\mathrm{H}_{3}$ was again supported. This finding was in accordance with Chadwick (2010).

The standard error of estimation of Model 1 was 0.74 . As a further measure of the strength of model fit, this standard error of the estimate was compared to the standard deviation and mean of organizational performance in Table 2. This indicated that without prior knowledge of the impact of HRM system as a whole, the organizational performance had mean about 5.45 (generally above industry average), with a Std. Dev $=0.86$ but with the regression model, the error of estimate was considerably lower, about 0.74 . Whereas, the standard error of estimation for Models 2, 3, 4, 5 and 6 were $0.81,0.84,0.85,0.85$ and 0.83 respectively, these were although lower than the standard deviation of organizational performance (Std. Dev $=0.86$ ) but higher enough than Model 1. This showed the strength of predicted HRM system model in decreasing the degree of deviation of organizational performance.

The regression coefficient of organizational performance for HRM system was $(B=0.635, p<0.01)$ significant. This beta value indicated the importance of HRM system (independent variable) in predicting the organizational performance. This regression coefficient was higher than all of the individual HRM practices' coefficients. So overall HRM system was more able predict the organizational performance as compare to the individual HRM practices. Here $\mathrm{H}_{3}$ was confirmed which stated that HRM system is more able to enhance the organizational performance than a sum of individual HRM practices.

\section{Conclusion}

Based on RBV, the purpose of this study was to empirically test that internally consistent and complementary HR practices in the HR system are more able to predict and enhance the organizational performance than the sum of individual practices. This paper has highlighted 
the importance of specific HRM system and its components, presence of different approaches to synergy in that HRM system and its ability to enhance the organizational performance.

The major finding of this research study has highlighted that the configurational approach to synergy or the HRM system as a whole has an ability to explain $27.5 \%$ of variation in the organizational performance as compare to $25 \%$ of variation explained by the sum of individual HRM practices. Similarly, the strong correlations present among various practices of HRM confirmed this that these practices were interdependent upon each other. But this interdependency plays more of its multiplicative and synergistic role as a HRM system because it was more able to explain variation in the organizational performance $\left(R^{2}=0.275, p<0.01\right)$ and more able to predict the organizational performance $(B=0.635, p<$ $0.01)$. Although the sum of individual HRM practices was also able to explain the enough variation $\left(\Sigma R^{2}=0.25\right)$ in the organizational performance but they were not able to predict and enhance the organizational performance individually. Hence, individuality carries no synergistic effects. Whereas, synergistic effects of configurational HRM system has explored the synergistic power to its highest possible values by enhancing organizational performance more than sum of individual HRM practices. HRM system has more ratio of explained variation in the organizational performance to unexplained variation, decreased overall model's standard error of estimation and finally more ability to predict the organizational performance. These all evidences indicated that each internally consistent component of HRM system has some configurational or multiplicative or additive synergistic effects (Chadwick, 2010) in enhancing the organizational performance. Hence, this research study confirmed that the whole is greater than the sum of individual parts. For managers, especially HRM managers, the success key to tap the interactive synergy is to send the centralized directions regarding all the HRM practices to maximize the overall configurational effect of HR bundle.

\section{REFERENCES}

Alam GM (2009). Can governance and regulatory control ensure private higher education as business or public goods in Bangladesh? Afr. J. Bus. Manage., 3(12): 890-906.

Alam GM (2009). The role of science and technology education at network age population for sustainable development of Bangladesh through human resource advancement. Sci. Res. Essays, 4(11): 1260-1270.
Alam GM, Hoque KE, Oloruntegbe KO (2010). Quest for a better operation system in Education: Privatization, Teacher Educationalization or Voucherilization: glimpsing from consumer and product perspectives. Afr. J. Bus. Manage., 4(6): 1202-1214.

Baird L, Meshoulam I (1988). Managing two fits of strategic human resource management. Acad. Manage. Rev., 13(1): pp. 116-128.

Barney JB (1991). Firm resources and sustained competitive advantage. J. Manage., 17(1): 99-120.

Barney JB, Wright PM (1998). On becoming a strategic partner: The role of human resources in gaining competitive advantage. Hum. Resour. Manage., 37(1): 31-46

Bird A, Beechler S (1995). Links between business strategy and human resource management strategy in U.S.-Based Japanese subsidiaries: An empirical investigation. J. Int. Bus. Stud., 26(1): $23-46$.

Chadwick C (2010). Theoretical insights on the nature of performance synergies in human resource system: Toward greater precision. Hum. Resour. Manage. Rev., 20: 85-101.

Colvin AJ, Boswell WR (2007). The problem of action and interest alignment: Beyond job requirements and incentive compensation. Hum. Resour. Manage. Rev., 17: 38 - 51.

Conant JS, Mokwa MP, Varadarajan PR (1990). Strategic type, Distinctive competencies and organizational performance: A multiple measure-based study. Strat. Manage. J., 11(5): 365-383.

Delery JE, Doty DH (1996). Modes of Theorizing in Strategic Human Resource Management: Tests of Universalistic, Contingency, and Configurational Performance Predictions. Acad. Manage. J., 39(4): 802-835.

Delery JE (1998). Issues of fit in strategic human resource management: Implications fro research. Hum. Resour. Manage., 8 (3): $289-309$.

Govindarajan V (1988). A contingency approach to strategy implementation at the business-unit level: Integrating administrative mechanisms with strategy. Acad. Manage. J., 31(4): 828-853.

Green KW Jr (2002). Just-in-time selling: relation to market orientation, organizational structure and organizational performance. Louisiana Tech University, Ruston, LA., Doctor of Business Administration dissertation.

Guerrero S, Barraud-Didier V (2004). High-involvement practices and performance of French firms. Int. J. Hum. Resour. Manage., 15: 1408-1423.

Hair JF, Bush RP, Ortinau DJ (2003). Marketing Research: Within a changing information environment. North America; McGraw-Hill.

Huang $T$ (2001). The effects of linkage between business and human resource management strategies. Person. Rev., 30(2): 132-151.

Huselid MA, Jackson SE, Schuler RS (1997). Technical and strategic human resource management effectiveness as determinants of firm performance. Academy of Management Journal, 40(1): 171-188

Milgrom P, Roberts J (1992). Economics, Organization, and Management. Englewood Cliffs, NJ: Prentice-Hall.

Michie J, Sheehan M (2005). Business strategy, human resources, labour market flexibility and competitive advantage. Int. J. Hum. Resour. Manage., 16: 445-464.

Mayson S, Barrett R (2006). The 'science' and 'practice' of HRM in small firms. Hum. Resour. Manage. Rev., 16: 447 - 455.

Wang D, Shyu C (2008). Will the strategic fit between business and HRM strategy influence HRM effectiveness and organizational performance? Int. J. Manpower, 29 (2): 92 -110.

Wei L (2006). Strategic Human Resource Management: Determinants of Fit. Res. Pract. Hum. Resour. Manage., 14(2): 49-60.

Wright PM, McMahan GC (1992). Theoretical perspectives for strategic human resource management. J. Manage., 18(2): 295-320. 